\title{
Endovascular repair of abdominal aortic aneurysm in octogenarians: clinical outcomes and complications
}

\author{
Sneha Raju, MD \\ Naomi Eisenberg, MEd, PT \\ Janice Montbriand, PhD \\ Graham Roche-Nagle, MD
}

Presented at the Canadian Society for Vascular Surgery Annual General Meeting, Sept. 15-16, 2017,

Banff, Alta.

\section{Accepted Nov. 5, 2019}

\section{Correspondence to:}

G. Roche-Nagle

218-6PMB, Peter Munk Cardiac

Centre

Toronto General Hospital

200 Elizabeth St

Toronto ON M5G 2C4

graham.roche-nagle@uhn.ca

DOI: $10.1503 /$ cjs.009019
Background: Endovascular aneurysm repair (EVAR) is associated with decreased perioperative morbidity and mortaliy in comparison with open repair, and thus octagenarians are traditionally offered EVAR given their age and medical comorbidities. The aim of this study was to investigate outcomes and predictors of complications associated with EVAR in octogenarians.

Methods: We conducted a retrospective chart review of consecutive patients aged 80 years and older who received an EVAR between August 2010 and January 2017 at a single centre in Toronto, Ontario. We conducted univariate comparisons and then completed logistic regression to determine predictors of complications. We used Kaplan-Meier analysis to explore survival times.

Results: A total of 154 octogenarians underwent an EVAR during the study period for an infrarenal aneurysm with a mean size of 64.8 (standard deviation [SD] 12.7) mm. The mean age of the patients was 84.1 (SD 3.7) years, and most patients (81\%) were men. Eighteen patients presented with a ruptured abdominal aortic aneurysm (AAA). Ninety-five (62\%) patients sustained a complication. Fifty percent of patients experienced an intraoperative complication. A majority of these (77\%) resulted in an endoleak, with type II endoleaks requiring no further intervenion being the most common $(58 \%, n=45)$. The remaining complications $(n=70)$ occurred postoperatively, with myocardial ischemia $(n=24)$ and dysrhythmias $(n=10)$ being the most common. Past aortic surgery $\left(\chi^{2}=8.62, p=0.014\right.$, Cramer $V=$ 0.27 ) was found to be a multivariate predictor of complications. Most patients (88\%) continued follow-up to an average of 20.9 months. Twenty-one patients (13\%) died. Nine of these deaths (43\%) occurred during the index admission and involved a ruptured AAA. Past aortic surgery was the only predictor of vascular complications. The mean survival time after EVAR was 57.63 months for patients without events.

Conclusion: Endovascular aneurysm repair in octogenarians is a suitable form of therapy with acceptable short- and long-term results in the elective setting. Past aortic surgery was a predictor of complications in this population.

Contexte : La réparation endovasculaire de l'anévrisme (REVA) est associée à une diminution de la morbidité et de la mortalité périopératoires comparativement à la chirurgie ouverte, c'est pourquoi on offre habituellement la REVA aux octogénaires, compte tenu de leur âge et de leurs comorbidités. Le but de cette étude était d'analyser l'issue de la REVA et les prédicteurs de complications chez les octogénaires.

Méthodes : Nous avons procédé à une analyse rétrospective des dossiers de patients de 80 ans et plus consécutifs soumis à une REVA entre août 2010 et janvier 2017 dans un établissement de Toronto, en Ontario. Nous avons effectué des comparaisons univariées, puis une analyse de régression logistique pour dégager les prédicteurs de complications. C'est l'analyse de Kaplan-Meier qui a permis d'explorer la survie.

Résultats : En tout, pendant la période de l'étude, 154 octogénaires ont subi une REVA pour un anévrisme infrarénal dont la dimension moyenne était de 64,8 $\mathrm{mm}$ (écart-type [É.-T.] 12,7 mm). L'âge moyen des patients était de 84,1 ans (É.-T. 3,7 ans) et la majorité des patients (81\%) étaient des hommes. Dix-huit patients ont présenté une rupture d'anévrisme de l'aorte abdominale (AAA). Quatre-vingt-quinze patients (62\%) ont connu une complication. Cinquante pour cent des patients ont eu une complication peropératoire. Une majorité des complications (77\%) ont causé des endofuites, le plus fréquemment de type II, ne nécessitant pas d'autres interventions $(58 \%, n=$ 45). Les autres complications $(n=70)$ sont survenues en période postopératoire et les plus fréquentes ont été l'ischémie myocardique $(n=24)$ et la dysrythmie $(n=10)$. Des antécédents de chirurgie à l'aorte $\left(\chi^{2}=8,62, p=0,014\right.$, test $V$ de Cramer $\left.=0,27\right)$ se sont révélés être un prédicteur multivarié de complications. La plupart des patients $(88 \%)$ ont maintenu le suivi pendant une durée moyenne de 20,9 mois. Vingt-et-un patients (13\%) sont décédés. Neuf de ces décès (43\%) se sont produits pendant l'admission index et impliquaient une rupture de l'AAA. Des antécédents de chirurgie à l'aorte ont été le seul prédicteur des complications vasculaires. La survie moyenne après la REVA a été de 57,63 mois pour les patients n'ayant présenté aucune complication.

Conclusion : La REVA est une forme de traitement qui convient aux octogénaires et qui donne des résultats acceptables à court et à long terme dans un contexte de chirurgie non urgente. Des antécédents de chirurgie à l'aorte se sont révélés être un prédicteur de complications dans cette population. 
L

ife expectancy for Canadians has increased steadily, with the 2017 census reporting an average of 80.7 years. ${ }^{1}$ Imaging has revealed that the prevalence of abdominal aortic aneurysms (AAAs) rises from $1 \%$ in people aged 55-60 years to $10 \%$ in octogenarians. ${ }^{2,3}$ There are 2 main treatment options: open repair and minimally invasive endovascular aneurysm repair (EVAR). Age is an independent risk factor for mortality after AAA repair. ${ }^{4}$ Endovascular aneurysm repair, which was introduced in the 1990s, is now being offered to a wider range of patients who are considered poor candidates for open surgery. Mortality associated with unrepaired aneurysms increases exponentially with aneurysm size: the 1-year risk of rupture is $3 \%-15 \%$ for $5-$ to $6-\mathrm{cm}$ aneurysms, whereas it is $30 \%-50 \%$ for 7 - to 8 -cm aneurysms. ${ }^{5}$ Additionally, aneurysms in octogenarians have an increased risk of rupture, ${ }^{6}$ with two-thirds of ruptures occurring in patients older than 75 years, and this is associated with a $69 \%$ mortality risk. ${ }^{7}$ Elective EVAR is aimed at preventing fatal rupture, and Society for Vascular Surgery guidelines recommend repair at $5.5 \mathrm{~cm} .{ }^{5}$ Given that the octogenarian population is growing, it is becoming increasingly important to consider surgical care on a case-by-case basis for this patient population and offer it when warranted.

Endovascular aneurysm repair is increasingly being preferred in the octogenarian population because it is associated with decreased perioperative morbidity and early survival benefits compared with open repair. ${ }^{8,9}$ Studies have shown that surgical treatment of aneurysms in octogenarians increased their life expectancy. ${ }^{10}$ Further, there have been several large studies showing that EVAR in octogenarians is associated with mortality and morbidity rates comparable to those of younger patients, making it a suitable modality of treatment for patients older than 80 years. ${ }^{11,12}$ On the other hand, long-term results of the EVAR 2 trial showed that in patients ineligible for open repair, EVAR decreased aneurysm-related mortality but had no effect on overall life expectancy. ${ }^{13}$ Given the controversy over the benefits of EVAR in an older population, it is imperative to create tools to aid in patient selection. In the present study, our aims were to (a) outline clinical outcomes of patients older than 80 years receiving EVAR in a large Canadian centre, (b) assess postoperative complications and their impact on mortality and (c) explore predictors of mortality.

\section{Methods}

\section{Study population}

We performed a retrospective analysis of all patients in the Vascular Quality Initiative (VQI) database at the Toronto General Hospital who underwent infrarenal endovascular aneurysm repair from August 2010 to January 2017. The Society for Vascular Surgery Vascular
Quality Initiative (SVS-VQI) was the source of prospectively collected data. ${ }^{13}$ The patient cohort of interest was defined as patients older than 80 years who were being treated for infrarenal aneurysms with amenable anatomy. Patients receiving a concomitant visceral intervention or thoracic endovascular aneurysm repair (TEVAR) were excluded. Device selection and vascular access were evaluated with multislice preoperative computed tomography (CT) with multiple 3-dimensional reconstructions, angiography at the time of catheterization and arterial duplex studies. Anatomic exclusion criteria included narrowed iliac arteries $(<7 \mathrm{~mm}$ diameter), conical or short $(<10 \mathrm{~mm})$ aortic neck and/or neck angulation greater than $60^{\circ}$. The University Health Network Research Ethics Board approved this study.

\section{Endovascular repair procedure}

The procedural approach for each patient was selected on the basis of factors such as tortuosity, calcification, diameter, plaque burden and aneurysms as determined by CT angiography and ultrasonography. When access was deemed to be poor, a surgical cut-down was completed with femoral endarterectomy as needed. Endovascular aneurysm repair was performed according to standard instructions for use. Percutaneous closure was performed using the Perclose technique using the Perclose ProGlide Suture-Mediated Closure System (Abbott Cardiovascular). ${ }^{14}$

Follow-up was standardized to 1, 6 and 12 months after the procedure and every 6-12 months thereafter. Each follow-up visit included CT angiography or abdominal duplex imaging, according to the surgeon's preference.

\section{Data collection and outcomes}

We collected data on patients' demographic characteristics and comorbidities, 30-day (operative) and long-term mortality, postoperative and intraoperative complications and other variables, reintervention, length of hospital admission, and 30-day readmissions. The primary outcomes of the study were intraoperative and postoperative complications. Postoperative complications were defined as any complication that occurred after surgery and before discharge. The secondary outcomes included discharge status, length of follow-up, mortality, reintervention and length of hospital stay. All patients were monitored in a step-down unit for 12-24 hours before being discharged home or transferred to a surgical floor.

\section{Statistical analysis}

Categorical data were expressed as number of patients and frequencies (percentages) and were compared with Pearson correlations, $\chi^{2}$ analysis or the Fisher exact test. Continuous variables were expressed as means with 
standard deviations (SDs) or $95 \%$ confidence intervals (CIs) and compared using Mann-Whitney $U$ tests. Demographic characteristics, comorbidities, intraoperative characteristics and postoperative characteristics were compared between patients who experienced a complication and those who did not. All comparisons were 2 -sided, and a $p$ value of less than 0.05 was considered significant. Variables found to be significantly related to complications in univariate analysis $(p<0.05)$ were included in the final prediction model. Given complete separation of data, we report the likelihood ratio for the Fisher exact test as a surrogate for logistic regression. Further, we used the Cramer $V$, a $\chi^{2}$-based measure of association. The Cramer $V$ equals 0 when there is no relationship between the 2 variables, and it has a maximum value of 1 .

Mortality analysis between the 2 groups was performed using Kaplan-Meier curves with events compared using log-rank tests $(p<0.05)$. All statistical analyses were performed using SPSS version 23 (IBM).

\section{Results}

\section{Baseline characteristics}

A total of 154 patients aged 80 years and older underwent EVAR during the study period. Most were men $(n=124$, $80.5 \%)$ who lived at home $(n=147,96.1 \%)$. The mean age of the study cohort was 84.1 (SD 3.7) years. Most (96.1\%) of these patients were considered unfit for open repair because of their comorbid status. Thirteen patients were older than 90 years of age; the oldest was 96 years of age. The maximum AAA diameter of cases at presentation was 64.8 (SD 12.7) $\mathrm{cm}$. Although the study patients had a significant burden of hypertension, smoking history and chronic obstructive pulmonary disease, only a minority had severe cardiac disease and end-stage renal disease. Most patients did not have a history of previous vascular surgery. The baseline characteristics of octogenarians who experienced a complication and those who did not are compared in Table 1.

\section{Intraoperative and postoperative factors}

Device manufacturers included Cook $(n=132,85.7 \%)$, Medtronic $(n=15,9.7 \%)$, Vascutek $(n=2,1.3 \%)$, Endologix $(n=2,1.3 \%)$, Cordis $(n=2,1.3 \%)$ and Gore $(n=1,0.6 \%)$. Twenty percent of cases $(n=31)$ were completed in an urgent fashion; 18 patients presented with ruptured AAAs (rAAAs) and 13 were symptomatic cases. Mean procedure time was $154.2 \pm 74.2$ minutes. Intraoperative blood loss and use of blood transfusions were minimal (Table 2). Eight patients (5.2\%) underwent concomitant surgical repair and 4 patients $(2.6 \%)$ sustained a complication that required conversion to open surgery.
Postoperatively, patients spent less than 1 day in the surgical step-down unit on average. Most patients $(n=131$, $85.6 \%)$ were discharged home after an average stay of $4.58 \pm 5.98$ days. For elective cases, the average length of stay (LOS) was 4 days, with the median being 2 days. For all urgent cases, the average LOS was 9 days, with patients who had rAAAs and symptomatic AAAs requiring stays of 13 and 6 days, respectively. During an average follow-up of 20.9 months, 16 patients (10.4\%) needed reintervention and 10 patients $(6.5 \%)$ required readmission (Table 2$)$.

\section{Complications}

Seventy-eight patients (50.6\%) experienced an intraoperative complication. Seventy-seven percent of intraoperative complications entailed an endoleak; a majority $(58 \%, n=$ $45)$ of them were type II leaks requiring no further intervention (Fig. 1). In 5 cases (6\%) the leaks were type $1 \mathrm{~A}$, in 2 cases $(3 \%)$ they were type $1 \mathrm{~B}$, in 3 cases $(4 \%)$ they were type III and in 1 case (1\%) they were type IV. In 22 cases (28\%) the intraoperative complications were classified as "other" and were unrelated to leak, such as bleeding, hemodynamic instability, cardiac arrhythmias, cardiac arrest, arterial injury, graft extension because of common iliac artery injury, and abdominal compartment syndrome needing laparotomy.

An additional 43 patients ( $n=70$ total, $45.4 \%$ ) experienced a postoperative complication (Fig. 2). A majority $(54 \%)$ of these complications were cardiac in nature, including ischemia ranging from troponitis to symptomatic coronary artery disease $(34 \%, n=24)$, arrhythmias $(14 \%$, $n=10)$, and congestive heart failure $(6 \%, n=4)$. Of the patients with cardiac ischemia, only 8 patients $(33 \%)$ had electrocardiographic (ECG) changes or clinical symptoms. Access hematomas occurred in $6.5 \%(n=10)$ of all patients, with 1 requiring reintervention during the index hospital admission. Reinterventions were required in 8 patients (5.2\%), and these consisted of 3 embolectomies, 3 interventional procedures for dissections, 1 laparotomy for compartment syndrome and 1 thrombin injection. Respiratory complications occurred in 4 patients $(2.6 \%)$, 2 of whom developed pneumonia and 2 of whom required prolonged ventilator support. Other complications included surgical site infections $(n=3)$, limb ischemia $(n=3)$, intestinal ischemia $(n=1)$, stroke $(n=2)$ and dialysisdependent renal failure $(n=1)$.

\section{Predictors of complications}

Ninety-five patients $(61.7 \%)$ sustained an intraoperative and/or a postoperative complication. We excluded patients who sustained a type II endoleak and/or a rAAA from this analysis; as a result, 42 patients with complications were included in the analysis. Past aortic surgery $\left(\chi^{2}=4.73, p=0.033\right)$ was the only significant preoperative 
Table 1. Baseline characteristics of octagenarians who experienced a complication after endovascular aneurysm repair and those who did not

No. (\%) of patients*

\begin{tabular}{|c|c|c|c|c|c|}
\hline Characteristic & $\begin{array}{l}\text { All patients } \\
\quad n=154\end{array}$ & $\begin{array}{c}\text { Patients without } \\
\text { complications } \\
n=58\end{array}$ & $\begin{array}{c}\text { Patients with any } \\
\text { complications } \\
n=95\end{array}$ & $\begin{array}{l}\text { Patients with complications } \\
\text { other than type II endoleaks } \\
\text { and rAAA } \\
\qquad n=42\end{array}$ & $p$ value \\
\hline Age, mean $\pm S D$ & $84.1 \pm 3.7$ & $83.3 \pm 84.5$ & $84.5 \pm 3.6$ & $83.7 \pm 3.3$ & \\
\hline Sex, male & 124 (80.5) & $46(79.3)$ & $78(82.1)$ & 78 (81.3) & \\
\hline $\mathrm{BMI}$, mean $\pm \mathrm{SD}$ & $26.6 \pm 5.9$ & $27.6 \pm 4.2$ & $26.0 \pm 6.8$ & $26.6 \pm 5.1$ & \\
\hline \multicolumn{6}{|l|}{ Living status } \\
\hline Home & 147 (96.1) & 56 (96.6) & 91 (95.8) & 93 (96. 9) & \\
\hline Nursing home & $6(3.9)$ & $2(3.4)$ & $4(4.2)$ & $3(3.1)$ & \\
\hline Cerebrovascular disease & $20(13.2)$ & $6(10.3)$ & $14(15.1)$ & $9(9.4)$ & \\
\hline Coronary artery disease & $47(30.9)$ & 19 (32.8) & $28(29.8)$ & $34(35.4)$ & 0.40 \\
\hline Prior congestive heart failure & $21(13.8)$ & $8(13.8)$ & $13(13.8)$ & $16(16.7)$ & \\
\hline \multicolumn{6}{|l|}{ Stress test } \\
\hline Not done & 68 (44.4) & $26(44.8)$ & $42(44.2)$ & 36 (37.5) & \\
\hline Normal & 59 (38.6) & $23(39.7)$ & $36(37.9)$ & $41(42.7)$ & \\
\hline Ischemia & $15(9.8)$ & $6(10.3)$ & $9(9.5)$ & 11 (11.5) & \\
\hline $\mathrm{Ml}$ & $8(5.2)$ & $2(3.4)$ & $6(6.3)$ & $6(6.3)$ & \\
\hline Both ischemia and $\mathrm{MI}$ & $3(2.0)$ & $1(1.7)$ & $2(2.1)$ & $2(2.1)$ & \\
\hline \multicolumn{6}{|l|}{ EF } \\
\hline$<30 \%$ & $2(1.6)$ & $1(2.0)$ & $1(1.3)$ & $2(2.3)$ & \\
\hline $30 \%-50 \%$ & $20(16)$ & $7(14.3)$ & $13(17.1)$ & $15(17.2)$ & \\
\hline$>50 \%$ & 103 (82.4) & 41 (83.7) & 62 (81.6) & 70 (80.5) & \\
\hline COPD & $45(29.4)$ & $16(27.6)$ & $29(30.5)$ & $33(34.4)$ & 0.33 \\
\hline Diabetes & 19 (12.5) & $4(6.9)$ & $15(16)$ & $9(9.4)$ & 0.17 \\
\hline Hypertension & 122 (80.3) & 44 (75.9) & $78(83)$ & $76(79.2)$ & \\
\hline \multicolumn{6}{|l|}{ Smoker } \\
\hline Never & $36(23.7)$ & 15 (25.9) & $21(22.3)$ & $23(24.0)$ & \\
\hline Previous & 98 (64.5) & $34(58.6)$ & $64(68.1)$ & $58(60.4)$ & \\
\hline Current & $18(11.8)$ & $9(15.5)$ & $9(9.6)$ & $15(15.6)$ & \\
\hline $\begin{array}{l}\text { Preoperative hemoglobin, } \\
\text { mean } \pm \text { SD }\end{array}$ & $130 \pm 21.6$ & $134.7 \pm 15.6$ & $127.5 \pm 24.1$ & $132.4 \pm 17.9$ & 0.18 \\
\hline Family history of AAA & $8(5.3)$ & $3(5.2)$ & $5(5.4)$ & $6(6.3)$ & \\
\hline Previous CEA & $4(2.6)$ & $1(1.7)$ & $3(3.2)$ & $3(3.1)$ & \\
\hline Previous aneurysm repair & $9(5.9)$ & $2(3.4)$ & $7(7.4)$ & $5(5.2)$ & 0.16 \\
\hline Previous arterial bypass & $2(1.3)$ & $1(1.7)$ & $1(1.1)$ & $1(1.0)$ & \\
\hline $\begin{array}{l}\text { Previous arterial peripheral } \\
\text { intervention }\end{array}$ & $1(0.7)$ & $1(1.7)$ & - & $1(1.0)$ & \\
\hline Previous major amputation & $2(1.3)$ & $1(1.7)$ & $1(1.1)$ & $1(1.0)$ & \\
\hline Previous aortic surgery & $13(8.4)$ & $0(0)$ & 11(11.6) & $5(5.2)$ & 0.001 \\
\hline Unfit for AAA repair & $147(96.1)$ & 56 (96.6) & 91 (95.8) & 94 (97.9) & \\
\hline Maximum AAA diameter & $64.8(12.7)$ & $61.78(10.52)$ & 65 (13.78) & $62.5(11.2)$ & 0.54 \\
\hline Iliac aneurysm & $20(13.1)$ & $9(15.5)$ & $11(11.6)$ & $13(13.5)$ & 0.38 \\
\hline
\end{tabular}

predictor of complications in the univariate analysis. Several procedural variables differed between patients who experienced a complication and those who did not. Patients who experienced a complication had longer procedure times (159.52 v. $139.22 \mathrm{~min}, p=0.034)$, and more contrast use (105.71 v. $12145 \mathrm{~mL}, p=0.004)$ (Table 2). Postoperatively, patients who experienced a complication had increased rates of transfusion $(0.12$ v. 0.35 units; Mann-Whitney-Wilcoxon $=897, p=0.002$ ), longer ICU stays ( 0.67 v. $0.85 \mathrm{~d}, p=0.04)$ and longer hospital stays (3.21 v. $3.95 \mathrm{~d}, p=0.005$ ) (Table 2). In the final model, when the other variables in the model were held constant, past aortic surgery was associated with increased odds of complications $\left(\chi^{2}=8.62, p=0.014\right.$, Cramer $\left.V=0.27\right)$. 
Table 2. Intraoperative and postoperative variables for octogenarians who experienced a complication after endovascular aneurysm repair and those who did not

\begin{tabular}{|c|c|c|c|c|c|}
\hline \multirow[b]{2}{*}{ Variable } & \multicolumn{4}{|c|}{ No. (\%) of patients* } & \multirow[b]{2}{*}{$p$ value } \\
\hline & $\begin{array}{l}\text { All patients } \\
\quad n=154 \\
\text { average (sd) }\end{array}$ & $\begin{array}{c}\text { Patients without } \\
\text { complications } \\
n=58\end{array}$ & $\begin{array}{c}\text { Patients with } \\
\text { complications } \\
n=95\end{array}$ & $\begin{array}{l}\text { Patients with complications } \\
\text { other than type II endoleaks } \\
\text { and rAAA } \\
\qquad n=42\end{array}$ & \\
\hline $\begin{array}{l}\text { Urgency of surgery classified as } \\
\text { emergent }\end{array}$ & $31(20.3)$ & $8(13.8)$ & $23(24.2)$ & $6(10.4)$ & \\
\hline Total procedure time, min, mean $\pm S D$ & $154 \pm 74.2$ & $139 \pm 48.3$ & $164 \pm 85.1$ & $160 \pm 81.6$ & 0.034 \\
\hline Contrast, $\mathrm{mL}$, mean $\pm \mathrm{SD}$ & $122.3 \pm 66.9$ & $105.71 \pm 46.16$ & $132.47 \pm 75.34$ & $121.45 \pm 62.88$ & 0.004 \\
\hline Crystalloid, $\mathrm{mL}$, mean $\pm \mathrm{SD}$ & $2016.7 \pm 1078.7$ & $1913.79 \pm 763.98$ & $2079.47 \pm 1231.66$ & $1954.69 \pm 873.83$ & \\
\hline Estimated blood loss, $\mathrm{mL}$, mean $\pm \mathrm{SD}$ & $274.97 \pm 324.63$ & $214.74 \pm 160.2$ & $311.88 \pm 389.15$ & $270.47 \pm 264.29$ & 0.16 \\
\hline PRBC, units, mean \pm SD & $0.66 \pm 2.55$ & $0.11 \pm 0.45$ & $0.99 \pm 3.17$ & $0.18 \pm 0.821$ & 0.23 \\
\hline $\begin{array}{l}\text { Intraoperative complications (including } \\
\text { leaks) }\end{array}$ & $78(50.6)$ & - & $78(82.1)$ & $13(31.1)$ & \\
\hline Conversion to open surgery & $4(2.6)$ & $0(0)$ & $4(4.2)$ & $0(0)$ & \\
\hline Concomitant surgery & $8(5.2)$ & $4(6.9)$ & $4(4.2)$ & $0(0)$ & \\
\hline Transfusion, units, mean \pm SD & $1.07 \pm 3.4$ & $0.12 \pm 0.54$ & $1.65 \pm 4.2$ & $0.35 \pm 1.24$ & 0.002 \\
\hline $\begin{array}{l}\text { Stay in surgical step-down unit, } d, \\
\text { mean } \pm \text { SD }\end{array}$ & $0.97 \pm 1.03$ & $0.67 \pm 0.51$ & $1.15 \pm 1.21$ & $0.85 \pm 0.93$ & 0.04 \\
\hline Hospital length of stay, mean \pm SD & $4.58 \pm 5.98$ & $3.21 \pm 3.64$ & $5.41 \pm 6.84$ & $3.95 \pm 4.57$ & 0.005 \\
\hline \multicolumn{6}{|l|}{ Discharge status } \\
\hline Home & $131(85.6)$ & 56 (96.6) & 75 (78.9) & & \\
\hline Rehabilitation & $6(3.9)$ & $1(1.7)$ & $5(5.3)$ & & \\
\hline Nursing & $1(0.7)$ & - & $1(1.1)$ & & \\
\hline Dead & $9(5.9)$ & - & $9(9.5)$ & & \\
\hline Other & $6(3.9)$ & $1(1.7)$ & $5(5.3)$ & & \\
\hline Discharged home or not home & & & & & 0.21 \\
\hline No. of follow-up visits, mean \pm SD & $3.41 \pm 2.68$ & $3.24 \pm 2.77$ & $3.52 \pm 2.62$ & $3.25 \pm 2.57$ & 0.49 \\
\hline Readmissions related to EVAR & $10(6.5)$ & $3(5.2)$ & $7(7.4)$ & $2(4.8)$ & 0.65 \\
\hline Retreatment & $12(8.3)$ & $5(8.6)$ & $7(8.1)$ & $3(7.1)$ & \\
\hline $\begin{array}{l}\text { Average length of follow-up, mo, } \\
\text { mean } \pm \mathrm{SD}\end{array}$ & $20.9 \pm 18.3$ & $19.89 \pm 21.42$ & $21.61 \pm 16.13$ & $21.03 \pm 19.29$ & \\
\hline Total mortality & $21(13.6)$ & $6(10.3)$ & $15(15.8)$ & $5(11.9)$ & 0.71 \\
\hline Death in hospital & $9(5.8)$ & $0(0)$ & $9(9.5)$ & $2(4.8)$ & \\
\hline
\end{tabular}

\section{Mortality}

Overall mortality was $13.6 \%$ (21 patients) over 3043.61 observed person-months, and there were 130 censored cases (86\%). Forty-three percent of all deaths (9 patients) occurred during index admissions, and all of these patients had sustained a ruptured aneurysm. There were a total of 1997.62 observed person-months and 11 events (death) after discharge from the hospital, for a rate of 0.0055 events per person-month or 0.083 events per person-year. The average survival time was 58.39 months (95\% CI 51.35-65.43 mo) (Fig. 3). A Kaplan-Meier analysis was undertaken to investigate the relationship between any intraoperative or postoperative leak or complication and survival time.

There were 53 patients with no complications ( 6 events) and 42 with complications (5 events). The average survival time for those without complications was 58.96 (standard error [SE] 4.76) months, and it was 56.32 (SE 4.18) months for those with complications. No significant differences were found in survival time to death between these 2 populations $(p>0.05)$ (Fig. 4).

A further analysis investigated intraoperative leaks and complications separately from postoperative events (Fig. 5). There were 81 patients with no intraoperative complications (9 events) and 13 with intraoperative complications (2 events). There were no significant differences in survival time between those with and without intraoperative complications or leaks $(p>0.05)$. A further Kaplan-Meier analysis was undertaken to investigate whether time to death was related to postoperative complications. The mean survival time was 57.63 months (SE 4.182, 95\% CI 49.43-65.83 mo) for those without events, and it was 61.65 months (SE 3.69, 95\% CI 54.42-68.88 mo) for those with complications. There was no significant difference in survival time between the 2 groups $(p>0.05)$. 


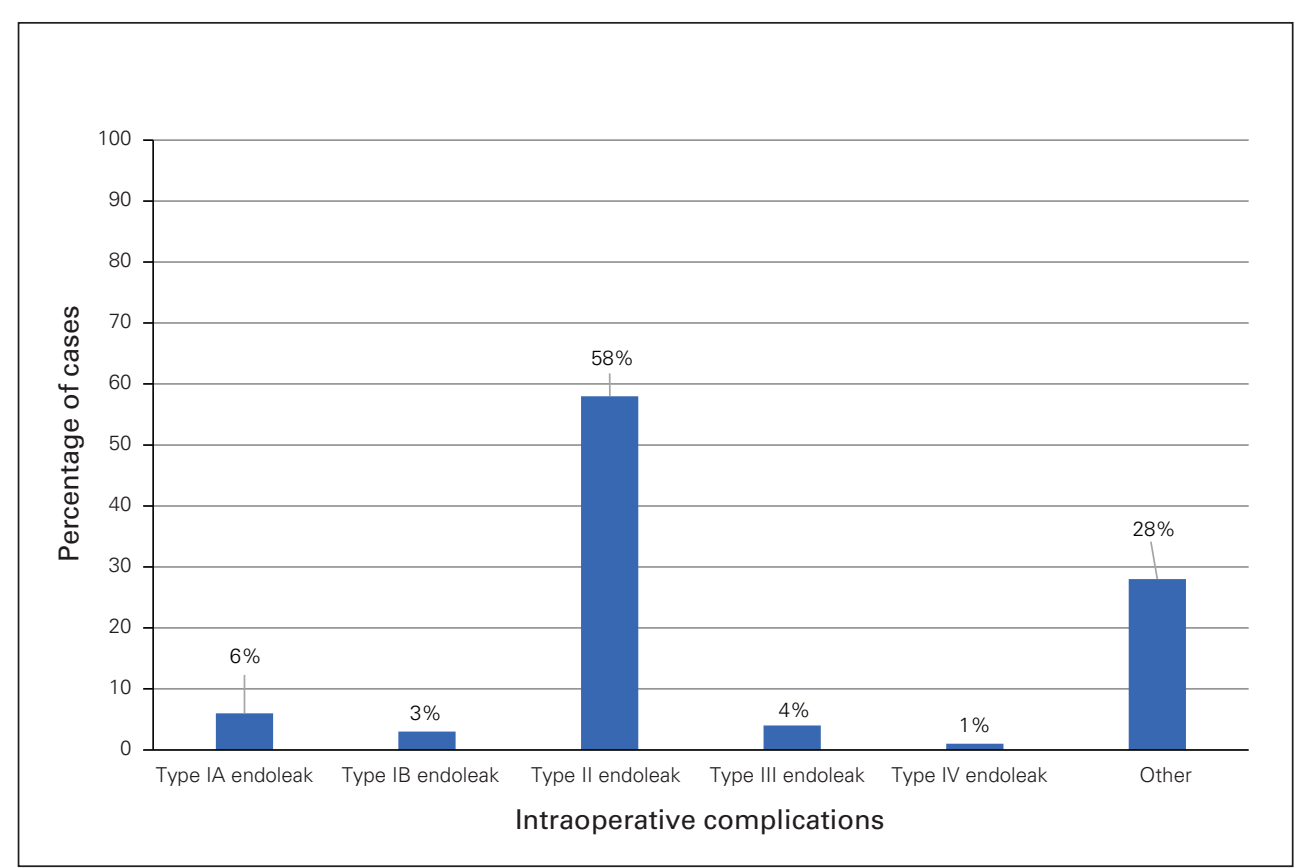

Fig. 1. Intraoperative complications experienced by study patients.

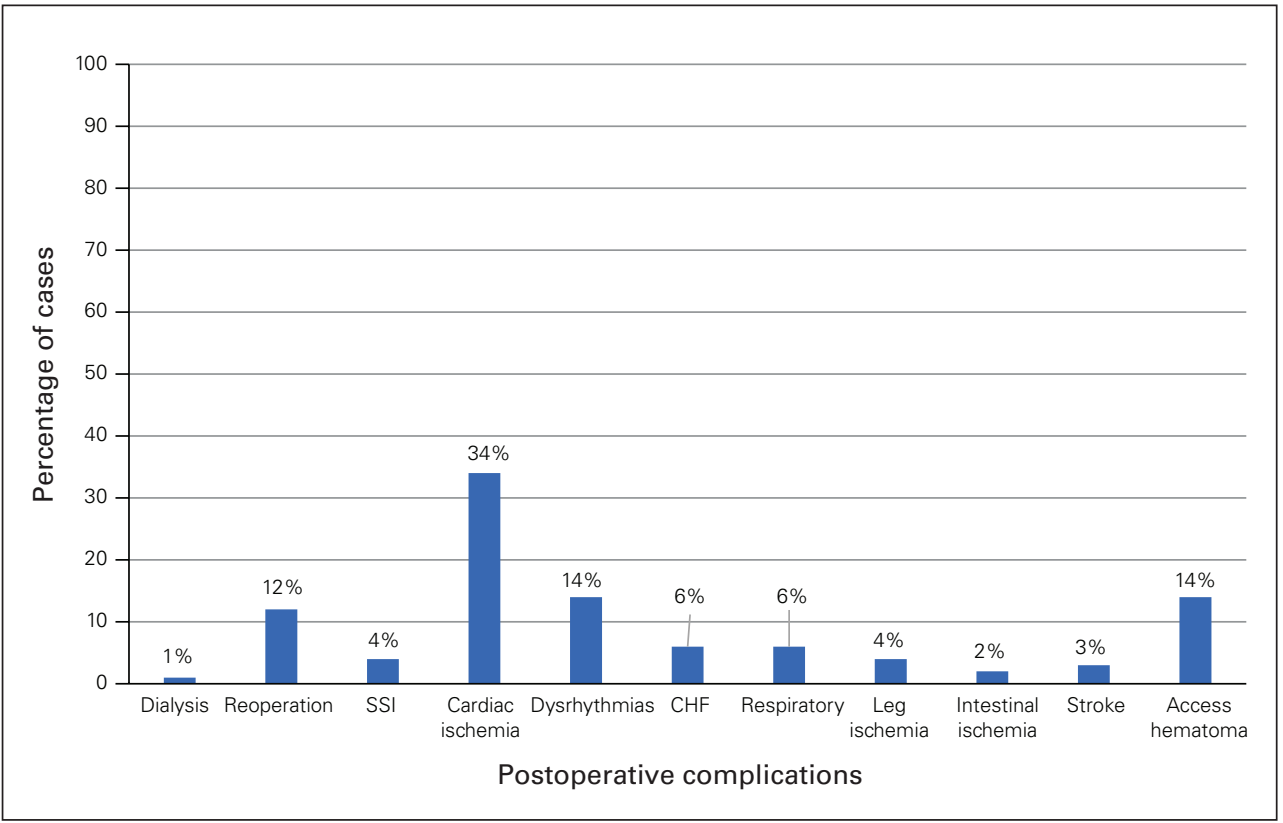

Fig. 2. Postoperative complications experienced by study patients. CHF = congestive heart failure; $\mathrm{SSI}=$ surgical site infection.

\section{Discussion}

Octogenarians constitute $25 \%$ of all patients who undergo EVAR $^{15}$ and the risk versus benefit of offering EVAR to this cohort is controversial. Decision-making in this area poses a challenge for vascular surgeons. The present paper included patients whose baseline characteristics were similar to those of patients in other published papers exploring outcomes in octogenarians. ${ }^{1,16-19}$ Although the goal of elective repair is to prevent fatal rupture, this benefit must be weighed against the risks associated with the procedure and anesthetic. Mortality rates for elective AAA repair range from $1.2 \%$ to $7 \% .{ }^{16,20,21}$ The perioperative mortality associated with EVAR in the VQI database including 21874 patients was $3.8 \%$ for octogenarians versus $1.6 \%$ in patients younger than 80 years. This represents a $223 \%$ increased risk of mortality in octogenarians. ${ }^{4}$ The present study reports $5.8 \%$ perioperative mortality in the octogenarian population. In other published surgical series, it ranged from $7 \%$ to $20 \% .4,11,17,18$ A recent metaanalysis pooled the results of 8 surgical series and reported a perioperative mortality rate of $3.73 \%$ in 5876 patients. $^{19}$ In contrast, younger patients had perioperative mortality rates of $0 \%-1.68 \% .{ }^{17-19}$ All patients who died perioperatively in the current study presented with ruptures, which inherently increased their mortality risk. Additionally, the average survival time in this series was 58 months, which is substantial given that the average life expectancy in Canada is 82 years and the average age at intervention is 84 years. This finding is similar to the literature, where the median survival time was 47 months, which reflects the fact that patients who underwent EVAR were healthier than their age-matched controls. ${ }^{17}$ Although higher than in the younger population, the rate of perioperative mortality is acceptable in octogenarians, especially given the excellent post-EVAR survival time. The present study showed that most patients maintained a good quality of life after surgery: $85.6 \%$ were discharged home and $3.9 \%$ to rehabilitation; fewer than $1 \%$ needed a nursing home. During our follow-up period, $6.5 \%$ needed a readmission and $7.1 \%$ needed retreatment for endoleaks and other complications. It is important, however, to note that the mean LOS in the study was 


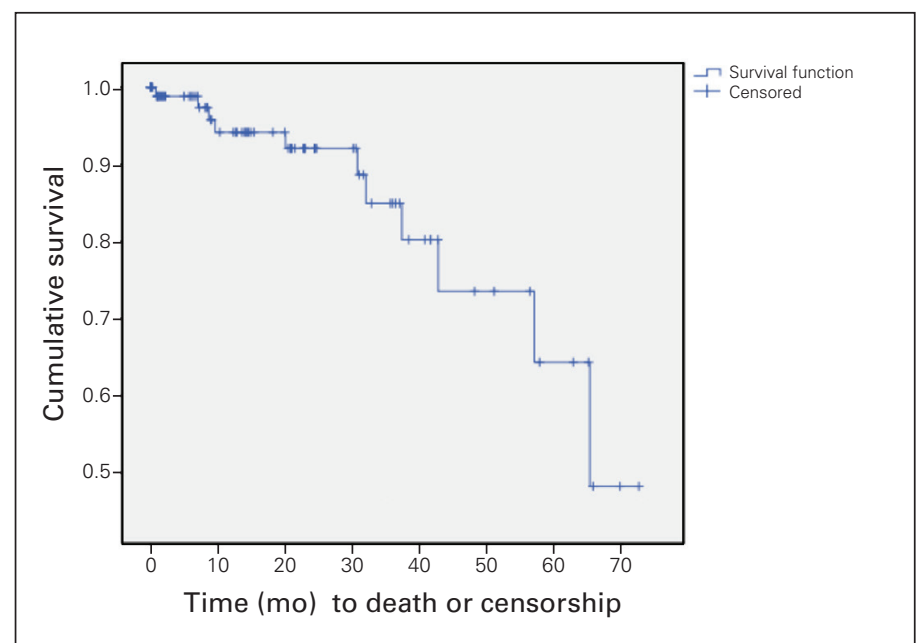

Fig. 3. Mortality analysis for the overall patient cohort.

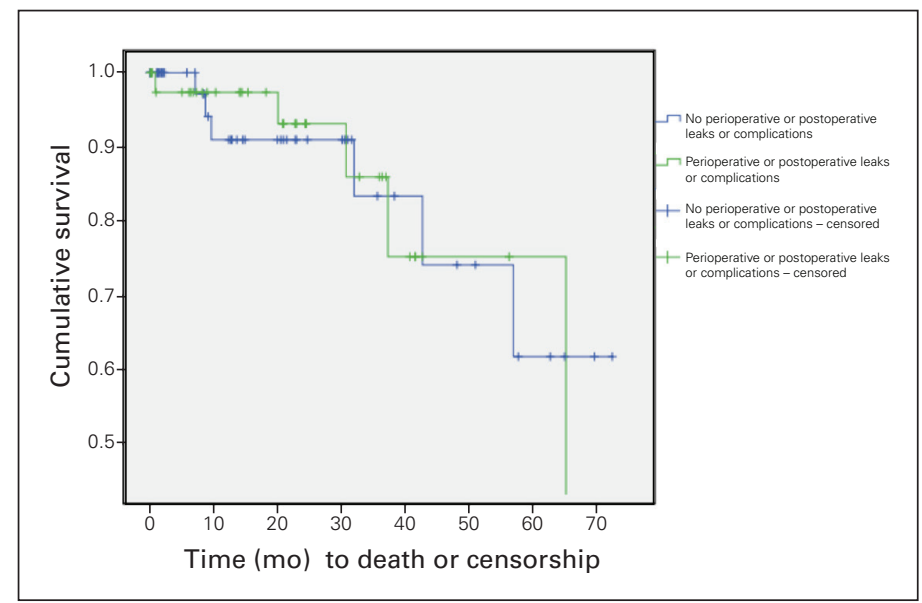

Fig. 4. Kaplan-Meier analysis to investigate the relationship between any intraoperative or postoperative leak or complication and survival time.
4.58 days. Other series have had higher LOS, ranging from 5.34 to 6.34 days in octogenarians. ${ }^{17,19}$ In contrast, a study from the American College of Surgeons National Surgical Quality Improvement Program (NSQIP) with 15000 patients reported an average LOS of 2.9 days in all patients. They also found that octogenarians had longer stays. ${ }^{22}$ This reflects the frail nature of this patient cohort and the need to use additional health care resources to get them back to baseline functional status.

Although several papers have explored predictors of complications in the EVAR population, literature in octogenarians is scarce. Given that decision-making with regard to patient selection is such an important aspect of care in this population, it is crucial to explore factors that put certain patients at higher risk of complications. In the general EVAR population, preoperative anatomy (AAA diameter, iliac tortuosity, neck calcification, number of patent sac branches), age, American Society of Anesthesiologists rating, creatinine, chronic obstructuve pulmonary disease and congestive heart failure have been shown to be predictors of worse postoperative outcomes. ${ }^{23-27}$ The present study specifically explored predictors in the octogenarian population and found that previous aortic surgery $(8.4 \%$ of the patients in our cohort) was an important predictor of all complications. It would be important to take this into consideration when offering EVAR to patients. There are several reasons why past aortic surgery could be a predictor of worse outcomes.

The present study found a substantial incidence of endoleaks in the perioperative period. However, only 16 patients needed intervention. Previous studies have shown that octogenarians are more likely to develop systemic complications, especially renal and pulmonary

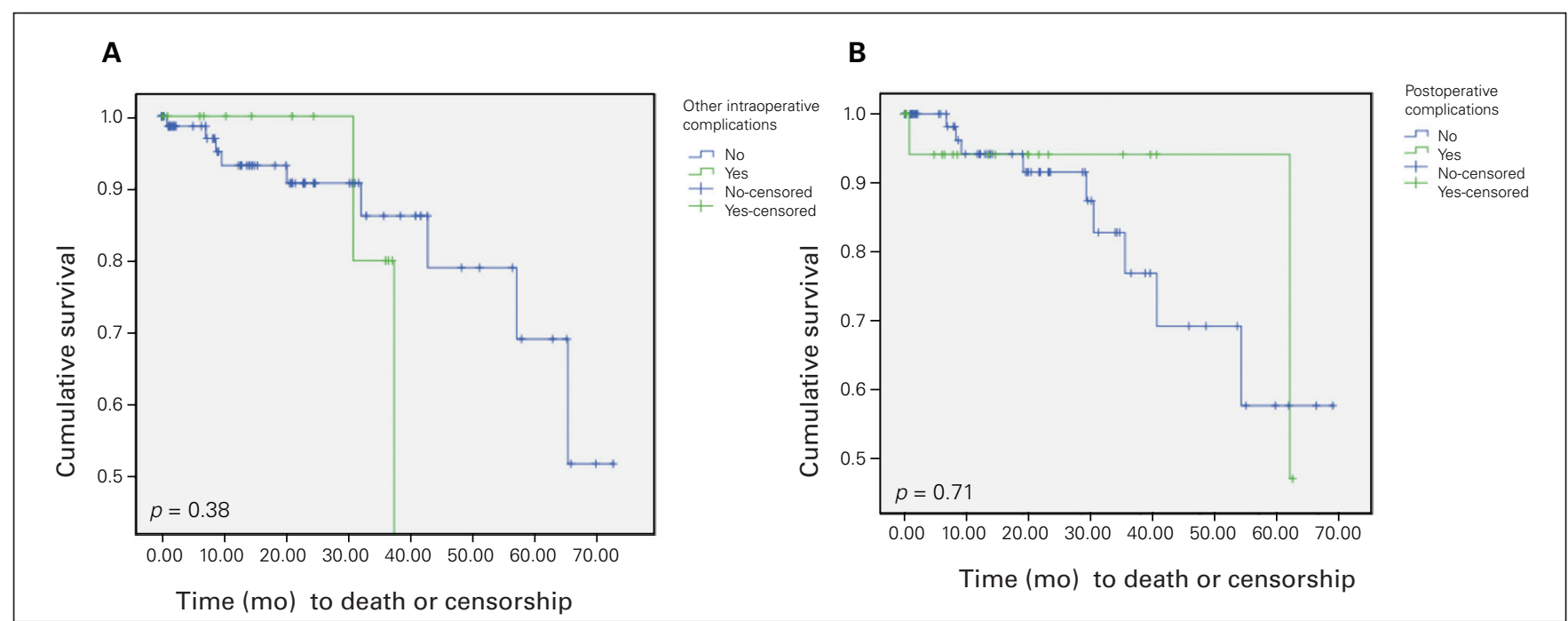

Fig. 5. (A) Kaplan-Meier analysis to investigate the relationship between any intraoperative leak or complication and survival time. Type II endoleaks and ruptured abdominal aortic aneurysms were excluded from the analysis. (B) Kaplan-Meier analysis to investigate the relationship between any postoperative leak or complication and survival time. 


\begin{abstract}
Box 1: Definition of postoperative myocardial infarction as per the Vascular Quality Initiative database
Troponin

Troponin rise alone should be reported if there was a rise and/or fall in cardiac biomarker values (preferably cardiac troponin) with at least 1 value above the 99th percentile upper reference limit in the absence of the 6 qualifying criteria for MI or sudden death as listed in the clinical MI definition below. Note that this requires at least 2 separate troponin values. Note that "rise" in troponin would imply that the troponin can be elevated at baseline (either preoperative or postoperative baseline) but not rise above whatever the patient's baseline level is. The lack of rising troponin above the baseline number would indicate that
\end{abstract} there was no additional MI.

\title{
ECG or clinical
}

Clinical MI should be reported when there is evidence of myocardial necrosis in a clinical setting consistent with acute myocardial ischemia. Any 1 of the following criteria meets the diagnosis for Ml:

1. A rise and/or fall of cardiac biomarkers (preferably troponin) with at least 1 of the values in the abnormal range for that laboratory (typically above the 99th percentile of the upper reference limit for normal subjects) together with at least 1 of the following manifestations of myocardial ischemia:

(a) ischemic symptoms such as angina, acute shortness of breath

(b) ECG changes indicative of new ischemia (new ST-T changes, new left bundle branch block, or loss of R wave voltage).

(c) development of pathological Q waves in 2 or more contiguous leads in the ECG (or equivalent findings for true posterior MI)

(d) imaging evidence of new loss of viable myocardium or new regional wall motion abnormality

(e) documentation in the medical record of the diagnosis of acute $\mathrm{MI}$ on the basis of the cardiac biomarker pattern in the absence of any items enumerated in items $1 \mathrm{a}$ to $1 \mathrm{~d}$ owing to conditions that may mask their appearance (e.g., perioperative infarct when the patient cannot report ischemic symptoms; baseline left bundle branch block or ventricular pacing)

2. $\quad$ ECG changes associated with $\mathrm{MI}$ can include the following (with or without prior symptoms):

(a) any $\mathrm{Q}$ wave in leads $\mathrm{V} 2-\mathrm{V} 3 \geq 0.02$ s or $\mathrm{OS}$ complex in leads $\mathrm{V} 2$ and $\mathrm{V} 3$

(b) Q wave $\geq 0.03 \mathrm{~s}$ and $\geq 0.1 \mathrm{mV}$ deep or $\mathrm{QS}$ complex in leads I, II, aVL, aVF or V4-V6 in any 2 leads of a contiguous lead grouping (I, aVL, V6; V4-V6; II, III and aVF)

(c) $R$ wave $\geq 0.04 s$ in $V 1-V 2$ and $R / S \geq 1$ with a concordant positive $T$ wave in the absence of a conduction defect

3. Imaging evidence of a region with new loss of viable myocardium at rest in the absence of a nonischemic cause. This can be manifest as: (a) echocardiographic, CT, MR, ventriculographic or nuclear imaging evidence of left ventricular thinning or scarring and failure to contract appropriately (i.e., hypokinesis, akinesis or dyskinesis)

(b) new fixed (nonreversible) perfusion defects on nuclear radioisotope imaging (e.g., MIBI, thallium)

(c) identification of an intracoronary thrombus by angiography or autopsy

4. Documentation in the medical record of the diagnosis of acute $\mathrm{Ml}$ on the basis of the cardiac biomarker pattern in the absence of any items enumerated in items a-d owing to conditions that may mask their appearance (e.g., perioperative infarct when the patient cannot report ischemic symptoms; baseline left bundle branch block or ventricular pacing).

5. Cardiac death with symptoms suggestive of myocardial ischemia and presumed new ischemic ECG changes or new LBBB, but death occurred before cardiac biomarkers were obtained, or before cardiac biomarker values would be increased.

Adapted from the Vascular Quality Initiative variables data dictionary. CT = computed tomographic; ECG = electrocardiographic; LBBB = left bundle branch block; $\mathrm{MI}=$ myocardial infarction; $\mathrm{MIBI}=$ myocardial perfusion imaging; $\mathrm{MR}=$ magnetic resonance.

ones. ${ }^{12,19}$ In the present study, cardiac complications were the most prevalent systemic complication, accounting for nearly $50 \%$ of all postoperative complications. Cardiac complications were defined as anything from troponitis to ECG changes to clinical symptoms as per the VQI database (Box 1). This creates a very low threshold for a positive outcome. Most of the cardiac complications could simply be explained as type 2 myocardial infarctions where risk modification is the only treatment. Renal complications requiring dialysis occurred in 1 patient in our entire cohort. Biebl and colleagues showed that there was a temporary rise in serum creatinine that was higher in the octogenarian population $(14 \%$ v. $5 \%)$; however, this was correlated with increased need for dialysis. ${ }^{18}$ Causes of renal impairment can include nephropathy induced by contrast material, thromboembolism and technical errors. ${ }^{28}$ Pulmonary complications were also rare, occurring in 4 patients. Importantly, complications were not correlated with long-term mortality but rather were associated with length of stay, length of procedure, blood loss and contrast use.

Limitations of the present study are that it involved the use of administrative data and was hypothesis driven.
Strengths include the consistent strategies used for patient selection, operative procedures and postoperative care. The study centre is a tertiary referral centre with a wide catchment area; thus, we believe that the findings from our patient population could be generalized to the general EVAR population. This study provides a detailed analysis of perioperative and postoperative complications and predictors that could not be sufficiently addressed in multicentre studies. Finally, self-assessments of quality of life would have provided a much-needed patient perspective.

\section{Conclusion}

Octogenarians are a growing population with AAA who require treatment. The results of this study corroborate existing literature supporting the use of EVAR in octogenarians. On average, the octogenarians in this study stayed in hospital for 4-5 days and were discharged home. The overall average survival was 58 months. Although octagenarians experience more perioperative mortality and morbidity than younger patients, EVAR can be performed safely in this patient group. Patient selection plays 
an important role in reducing complications after EVAR. Past aortic surgery was associated with complications in this population. Our findings suggest that octagenarians receiving EVAR are generally healthier than patients of similar age who do not undergo this procedure. Moving forward, we need to focus on frailty and overall health status as opposed to age in patient selection and prediction models. More work needs to be done to assess patient quality of life outcomes.

Affiliations: From the Faculty of Medicine, University of Toronto, Toronto, Ont. (Raju, Roche-Nagle); the Division of Vascular Surgery, Toronto General Hospital, University Health Network, University of Toronto, Toronto, Ont. (Raju, Roche-Nagle); and the Division of Obstetrical Anesthesia, Sunnybrook Health Sciences Centre, Toronto, Ont. (Eisenberg, Montbriand).

Competing interests: G. Roche-Nagle is a clinical proctor for Cook Medical. No other competing interests were declared.

Contributors: S. Raju and G. Roche-Nagle designed the study. S. Raju and N. Eisenberg acquired the data, which J. Montbriand G. RocheNagle analyzed. All authors wrote and critically reviewed the article. All authors gave final approval of the version to be published.

\section{References}

1. Bushnik T, Tjepkema M, Martel L. Health-adjusted life expectancy in Canada. Ottawa: Statistics Canada; 2018. Available: https://www150. statcan.gc.ca/n1/pub/82-003-x/2018004/article/54950-eng.htm (accessed 2019 Feb. 17).

2. Scott RA, Ashton HA, Kay DN. Abdominal aortic aneurysm in 4237 patients: prevalence, development and management over 6 years. $\mathrm{Br}$ f Surg 1991;78:1122-5.

3. Pleumeekers HJCM, Hoes AW, van der Does E, et al. Aneurysms of the abdominal aorta in older adults: The Rotterdam Study. Am 7 Epidemiol 1995;142:1291-9.

4. Hicks CW, Obeid T, Arhuidese I, et al. Abdominal aortic aneurysm repair in octogenarians is associated with higher mortality compared with nonoctogenarians. 7 Vasc Surg 2016;64:956-65.

5. Brewster DC, Cronenwett JL, Hallett JW Jr, et al. Guidelines for the treatment of abdominal aortic aneurysms. Report of a subcommittee of the Joint Council of the American Association for Vascular Surgery and Society for Vascular Surgery. 7 Vasc Surg 2003; 37:1106-17.

6. Kazmers A, Perkins AJ, Jacobs LA. Outcomes after abdominal aortic aneurysm repair in those $\leq 80$ years of age: recent Veterans Affairs experience. Ann Vasc Surg 1998;12:106-12.

7. Howard DP, Banerjee A, Fairhead JF, et al. Age-specific incidence, risk factors and outcome of acute abdominal aortic aneurysms in a defined population. Br 7 Surg 2015;102:907-15.

8. Parodi JC, Palmaz JC, Barone HD. Transfemoral intraluminal graft implantation for abdominal aortic aneurysms. Ann Vasc Surg 1991;5:491-9.

9. Park BD, Azefor NM, Huang CC, et al. Elective endovascular aneurysm repair in the elderly: trends and outcomes from the Nationwide Inpatient Sample. Ann Vasc Surg 2014;28:798-807.
10. O'Donnell TF, Darling RC, Linton RR. Is 80 years too old for aneurysmectomy? Arch Surg 1976;111:1250-7.

11. Prenner SB, Turnbull IC, Malik R, et al. Outcome of elective endovascular abdominal aortic aneurysm repair in octogenarians and nonagenarians. 7 Vasc Surg 2010;51:1354-9.

12. Fonseca R, Rockman C, Pitti A, et al. Intermediate-term EVAR outcomes in octogenarians. 7 Vasc Surg 2010;52:556-60.

13. United Kingdom EVAR Trial Investigators. Endovascular repair of aortic aneurysm in patients physically ineligible for open repair. $N$ Engl 7 Med 2010;362:1872-80.

14. Solomon LW, Fusman B, Jolly N, et al. Percutaneous suture closure for management of large French size arterial puncture in aortic valvuloplasty. F Invasive Cardiol 2001;13:592-6.

15. Park BD, Azefor NM, Huany CC, et al. Elective endovascular aneurysm repair in the elderly: trends and outcomes from the Nationwide Inpatient Sample. Ann Vasc Surg 2014;28:798-807.

16. O'Hara PJ, Hertzer NR, Krajewski LP, et al. Ten-year experience with abdominal aortic aneurysm repair in octogenarians: early results and late outcome. 7 Vasc Surg 1995;21:830-7.

17. Lagergren E, Chihade D, Zhan H, et al. Outcomes and durability of endovascular aneurysm repair in octogenarians. Ann Vasc Surg 2019;54:33-9.

18. Biebl M, Lau LL, Hakaim AG, et al. Midterm outcome of endovascular abdominal aortic aneurysm repair in octogenarians: a single institution's experience. 7 Vasc Surg 2004;40:435-42.

19. Han Y, Zhang S, Zhang J, et al. Outcomes of endovascular abdominal aortic aneurysm repair in octogenarians: meta-analysis and systematic review. Eur 7 Vasc Endovasc Surg 2017;54:454-63.

20. Patel R, Sweeting MJ, Powell JT, et al.; EVAR trial investigators. Endovascular versus open repair of abdominal aortic aneurysm in 15 -years' follow-up of the UK endovascular aneurysm repair trial (EVAR trial 1): a randomized controlled trial. Lancet 2016;388:2366-74.

21. Johnston KW; Canadian Society for Vascular Surgery Aneurysm Study Group. Nonruptured abdominal aortic aneurysm. 7 Vasc Surg 1994;20:163-70.

22. Nagarsheth K, Schor J, Singh K, et al. Predictors of hospital length of stay following endovascular abdominal aortic aneurysm repair: analysis of patients from the National Surgical Quality Improvement Program. 7 Vasc Surg 2015;61:65S.

23. Barnes M, Boult M, Maddern G, et al. A model to predict outcomes for endovascular aneurysm repair using preoperative variables. Eur $\mathcal{f}$ Vasc Endovasc Surg 2008;35:571-9.

24. Kaladji A, Daoudal A, Dumenil A, et al. Predictive models of complications after endovascular aortic aneurysm repair. Ann Vasc Surg 2017;40:19-27.

25. Schanzer A, Greenberg RK, Hevelone N, et al. Predictors of abdominal aortic aneurysm sac enlargement after endovascular repair. Circulation 2011;123:2848-55.

26. Scali ST, Beck AW, Chang CK, et al. Defining risk and identifying predictors of mortality for open conversion after endovascular aortic aneurysm repair. 7 Vasc Surg 2016;63:873-81.e1.

27. Wyss TR, Dick F, Brown LC, et al. The influence of thrombus, calcification, angulation, and tortuosity of attachment sites on the time to the first graft-related complication after endovascular aneurysm repair. 7 Vasc Surg 2011;54:965-71.

28. Kramer SC, Seifarth H, Pamler R, et al. Renal infraction following endovascular aortic aneurysm repair. 7 Endovasc Ther 2002;9:98-102. 